\title{
Effects of etanercept versus sulfasalazine in early axial spondyloarthritis on active inflammatory lesions as detected by whole-body MRI (ESTHER): a 48-week randomised controlled trial
}

\author{
I-H Song, ${ }_{1}^{1}$ KG Hermann, ${ }^{2}$ H Haibel, ${ }^{1}$ CE Althoff, ${ }^{2} \mathrm{~J}$ Listing, ${ }^{3}$ GR Burmester, ${ }^{4}$ A Krause, ${ }^{5}$ \\ M Bohl-Bühler, ${ }^{6}$ B Freundlich, ${ }^{7}$ M Rudwaleit, ${ }^{1} \mathrm{~J}$ Sieper ${ }^{1}$
}

\begin{abstract}
'Department of Rheumatology, Charité Medical University, Campus Benjamin Franklin, Berlin, Germany ${ }^{2}$ Department of Radiology, Charité Medical University, Campus Charité Mitte, Berlin, Germany ${ }^{3}$ German Rheumatism Research Center, Berlin, Germany ${ }^{4}$ Department of Rheumatology, Charité Medical University, Campus Charité Mitte, Berlin, Germany

${ }^{5}$ Department of Rheumatology, Charité Medical University, Campus Buch, Berlin, Germany Private Practice, Potsdam, Germany

${ }^{7}$ Division of Rheumatology, University of Pennsylvania, Philadelphia, USA
\end{abstract}

\section{Correspondence to}

Dr Joachim Sieper, Charité, Campus Benjamin Franklin, Med Clinic I, Rheumatology, Hindenburgdamm 30, 12200 Berlin, Germany; joachim.sieper@charite.de

Accepted 1 November 2010

\section{ABSTRACT \\ Purpose To evaluate the potential of etanercept versus sulfasalazine to reduce active inflammatory lesions on whole-body MRI in active axial spondyloarthritis with a symptom duration of less than 5 years. \\ Methods Patients were randomly assigned to etanercept $(n=40)$ or sulfasalazine $(n=36)$ treatment over 48 weeks. All patients showed active inflammatory lesions (bone marrow oedema) on MRI in either the sacroiliac joints or the spine. MRI was performed at weeks 0, 24 and 48 and was scored for active inflammatory lesions in sacroiliac joints and the spine including posterior segments and peripheral enthesitis by two radiologists, blinded for treatment arm and MRI time point.}

Results In the etanercept group, the reduction of the sacroiliac joint score from 7.7 at baseline to 2.0 at week 48 was significantly ( $p=0.02$ ) larger compared with the sulfasalazine group from 5.4 at baseline to 3.5 at week 48. A similar difference in the reduction of inflammation was found in the spine from 2.2 to 1.0 in the etanercept group versus from 1.4 to 1.3 in the sulfasalazine group between baseline and week 48 , respectively $(p=0.01)$. The number of enthesitic sites also improved significantly from 26 to 11 in the etanercept group versus 24 to 26 in the sulfasalazine group ( $p=0.04$ for difference). $50 \%$ of patients reached clinical remission in the etanercept group versus $19 \%$ in the sulfasalazine group at week 48

Conclusion In patients with early axial spondyloarthritis active inflammatory lesions detected by whole-body $\mathrm{MRI}$ improved significantly more in etanercept versus sulfasalazine-treated patients. This effect correlated with a good clinical response in the etanercept group.

The treatment of ankylosing spondylitis (AS) with tumour necrosis factor (TNF) alpha blocking agents has been shown to be highly effective. ${ }^{1-4}$ Shorter disease duration, together with young age, were among the best predictors for a major treatment response in several analyses. ${ }^{5-7}$ The new Assessment of SpondyloArthritis International Society (ASAS) criteria for axial spondyloarthritis were published recently covering both patients with and without radiographic sacroiliitis. ${ }^{8}$ Active inflammation of the sacroiliac joints as shown by MRI is an important part of these new criteria. ${ }^{9}$

Until now two clinical studies with TNF blockers have been performed in patients with non-radiographic axial spondyloarthritis showing a very good response in a high percentage of patients with a disease duration of less than 3 years. ${ }^{710}$

MRI is currently the best imaging method for the detection of active inflammation in the sacroiliac joints and the spine and an impressive reduction of such active inflammation could be demonstrated in the past in several trials treating AS patients with TNF blockers, ${ }^{10} 11$ but the treatment effect on other parts of the skeleton were not investigated by MRI.

Whole-body MRI may be an ideal tool to study not only the spine and sacroiliac joints but also the enthesial areas. ${ }^{12-14}$ Two previous studies demonstrated that whole-body MRI and conventional MRI showed a high correlation of active inflammation both in the investigation of the sacroiliac joints $^{15}$ and spine. ${ }^{16}$

In the current prospective randomised trial we investigated the effect of treatment with the TNF blocker etanercept in comparison with treatment with sulfasalazine on active bony inflammation in the whole skeleton by whole-body MRI as the primary outcome parameter over 12 months in patients with early axial spondyloarthritis with a symptom duration of less than 5 years.

\section{PATIENTS AND METHODS}

\section{Study design}

In this 48-week, randomised multicentre open-label trial (ClinicalTrials.gov identifier NCT00844142), 76 patients with non-steroidal anti-inflammatory drug (NSAID)-refractory axial spondyloarthritis were prospectively randomly assigned ${ }^{17}$ to etanercept $25 \mathrm{mg}$ given twice weekly subcutaneously $(n=40)$ or sulfasalazine $2-3$ g per day given orally according to the local rheumatologist's decision $(n=36)$ for treatment over 48 weeks. In the case of intolerance to sulfasalazine patients could be switched to methotrexate (15-20 mg weekly by mouth). The study was approved by an independent ethics committee.

\section{Inclusion and exclusion criteria}

Patients had to be 18-50 years of age and had to have a diagnosis of axial spondyloarthritis with a symptom duration of less than 5 years. The diagnosis was made based on the presence of chronic low back pain with a duration of at least 3 months and onset at less than 45 years of age. All patients had to have active inflammatory lesions (osteitis/bone marrow 
oedema) on whole-body MRI in either the sacroiliac joints or the spine plus three out of the following criteria: (1) inflammatory back pain; ${ }^{18}$ (2) good or very good response to NSAID; (3) one or more of the extraspinal manifestations such as uveitis, peripheral arthritis, enthesitis; (4) HLA-B27 positivity; (5) a positive family history for spondyloarthritis. ${ }^{891920}$ Retrospectively, all patients fulfilled the recently published ASAS classification criteria for axial spondyloarthritis. ${ }^{8}$ All patients had to have a Bath ankylosing spondylitis disease activity index (BASDAI) of 4 or greater $^{21}$ and a back pain score (BASDAI question 2) of 4 or greater, despite treatment with NSAID and had undergone investigation with the same whole-body MRI at weeks 0, 24 and 48. Treatment with disease-modifying antirheumatic drugs or $7.5 \mathrm{mg} /$ day or more of prednisone (or equivalent) had to be discontinued at least 4 weeks before initiation of the study.

\section{Outcome assessments}

The primary endpoint of this study was the change of active inflammatory lesions in the sacroiliac joints and spine as detected by MRI at 48 weeks. Secondary endpoints were the reduction of active inflammatory lesions on the posterior elements of the spine and a reduction of peripheral enthesitis on MRI, and the following clinical endpoints: BASDAI50, ASAS20 and 40 and ASAS partial remission. ${ }^{22} 23$

Other clinical and laboratory outcome assessments ${ }^{24}$ included BASDAI, Bath ankylosing spondylitis functional index (BASFI), ${ }^{25}$ Bath ankylosing spondylitis metrology index (BASMI) on an 11-point answer scale, ${ }^{26}$ a modified enthesitis Maastricht ankylosing spondylitis enthesitis score ${ }^{27}$ with an additional two sites at each knee (17 sites), a swollen joints count with 64 joints, ${ }^{28}$ patient's and physician's global assessments of disease activity and C-reactive protein (CRP). ${ }^{24}$ 29-31

\section{Whole-body MRI}

Whole-body MRI was performed on a $1.5 \mathrm{~T}$ scanner (Avanto TIM, Siemens, Germany) according to a previously described protocol. ${ }^{12} 14$ Due to the configuration of the coils, elbow, wrist, finger and toe joints could not be depicted.

\section{Scoring of whole-body MRI}

MRI were scored for active inflammatory lesions by two radiologists, blinded for treatment arm and MRI time point.

Active inflammatory lesions of the sacroiliac joints were scored according to a slightly modified previously described scoring method, ${ }^{32}$ with each sacroiliac joint divided into four quadrants. Each quadrant was scored for osteitis/bone marrow oedema as follows: 0 , absent (no osteitis); 1 , less than $33 \%$ of quadrant area; $2,33 \%$ or more to less than $66 \%$ of quadrant area; $3,66 \%$ or more of quadrant area with a maximum score of 24 . For the entire spine with 23 vertebral units, a recently described $^{33-35}$ scoring system was used to score active inflammation, resulting in a score between 0 and 69 , grade $0-3$ per vertebral unit. The sacroiliac joint and the spine MRI scores were calculated by using the mean values of both scorers. Scoring of the posterior elements included assessment for active inflammatory lesions of the facet joints, the costovertebral joints and the spinous processes in each vertebral unit. Posterior segments and peripheral enthesitis (active osteitis) were scored in consensus between both scorers with a 'yes' or 'no' answer for altogether 27 enthesitic sites of the non-axial skeleton (for further details see Althoff et al, manuscript in preparation).

The intraclass correlation coefficient (ICC) at baseline was 0.93 for assessing active inflammatory lesions of the spine and
0.96 for the sacroiliac joints. The ICC for change scores were 0.86 (spine) and 0.94 (sacroiliac joints), respectively.

\section{Statistical analysis}

Statistical analysis was performed as an intention-to-treat, last observation carried forward analysis. The non-parametric Mann-Whitney test was used to compare treatment groups at baseline. To compare changes in the sacroiliac joint and spine MRI scores between the treatment groups by taking the baseline status into account a non-parametric analysis of covariance (non-parametric ANCOVA) was used. ${ }^{36}$ In a sensitivity analysis the possible influence of the diagnosis at baseline (non-radiographic axial spondyloarthritis vs AS), HLA-B27 positivity, elevated CRP, clinical arthritis status on the primary outcome was examined by including those parameters as co-variables into the non-parametric ANCOVA model. One sulfasalazine patient with missing MRI data was excluded from the primary analysis. In 10 other patients (etanercept five, sulfasalazine five) with missing MRI data at week 48 the last observation carried forward method was applied to complete the data for the primary analysis. The non-parametric ANCOVA or, if appropriate, the usual parametric ANCOVA with the baseline value as a co-variable was applied to analyse secondary outcomes.

Furthermore, the parametric ANCOVA was used to investigate the correlation between changes in clinical parameters (BASDAI, BASFI, CRP, enthesitis count at week 48) and changes in MRI score (spine, sacroiliac joints, enthesitis) after adjustment for treatment and the baseline status in the corresponding clinical and MRI parameter. $\mathrm{p}$ Values less than 0.05 were considered statistically significant. The Holm procedure was applied to adjust for repeated significance testing of the primary outcome. ${ }^{37}$

\section{RESULTS}

\section{Baseline characteristics}

Of the 76 patients fulfilling the inclusion criteria, 40 were randomly assigned to receive etanercept and 36 sulfasalazine. The mean dose of sulfasalazine was $1688 \mathrm{mg}(\mathrm{n}=32)$ at week 24 and $1650 \mathrm{mg}(\mathrm{n}=30)$ at week 48; four patients were switched to methotrexate (15.0 mg weekly for each patient) because of intolerance to sulfasalazine. Patients' characteristics were similar, with no statistical difference between the etanercept and the sulfasalazine group (table 1-3).

All patients were active as shown by clinical parameters and positive MRI (table 2). At baseline, 94.6\% of the patients showed active inflammatory lesions in the sacroiliac joints, $47.3 \%$ in the spine, but only $5.4 \%$ in the spine but not in the sacroiliac joints.

\section{Primary and secondary MRI outcome parameters}

In the etanercept group, there was a clear reduction of the mean sacroiliac joint score from 7.8 at baseline to 2.4 at week 48 (table 2). After adjusting for the non-significantly different baseline MRI score, this reduction remained significantly $(\mathrm{p}=0.02)$ larger compared with the sulfasalazine group: 5.4 and 3.5 , respectively (table 2 ). Inflammation was thus reduced after 1 year of treatment by $69.2 \%$ in the etanercept group in comparison to $35.2 \%$ in the sulfasalazine group. The same was true when the reduction of inflammation in the spine was compared between the two groups $(p=0.01)$ (table 2$)$. The results of the primary outcome remained significant after taking the presence of two co-primary endpoints (MRI sacroiliac joint and spine scores) into account. In the sensitivity analysis similar significant 
results were found for the primary endpoints. Figure 1 shows MRI examples for the reduction of active inflammatory lesions in the sacroiliac joints, the spine and enthesitis. The improvement on the patient level is shown in the probability plots in figure 2 .

When analysing only patients with at least one active spinal lesion ( $n=35)$, the difference in the improvement of the MRI spine score was even more remarkable (etanercept baseline 4.2, week 48 1.9; sulfasalazine baseline 3.7, week 48 3.2), resulting in a reduction of $55 \%$ in the etanercept group versus $14 \%$ in the sulfasalazine group $(\mathrm{p}=0.03)$.

At week 48 six patients from the etanercept compared with two patients from the sulfasalazine treatment group became free of any active inflammatory lesions on MRI at any site in the skeleton including the spine, sacroiliac joints, entheses and posterior elements.

Table 1 Baseline characteristics of study patients by treatment group

\begin{tabular}{|c|c|c|c|}
\hline Characteristic & Etanercept group $(n=40)$ & Sulfasalazine group $(n=36)$ & All patients $(n=76)$ \\
\hline Age in years, mean $( \pm S D)$ & $34.5(8.6)$ & $32.8(8.4)$ & $33.7(8.5)$ \\
\hline Disease duration (back pain duration) in years, mean $( \pm S D)$ & $2.6(1.7)$ & $3.0(1.8)$ & $2.9(1.7)$ \\
\hline Male patients, $\mathrm{n}(\%)$ & $23(57.5)$ & $21(58.3)$ & $44(57.9)$ \\
\hline HLA-B27 positive, $\mathrm{n}(\%)$ & $34(85)$ & $28(77.8)$ & $62(81.6)$ \\
\hline Elevated CRP (CRP >5 mg/l), $\mathrm{n}(\%)$ & $24(60.0)$ & $16(44.4)$ & $40(52.6)$ \\
\hline Clinical arthritis, $\mathrm{n}(\%)$ & $15(37.5)$ & $18(50.0)$ & $33(43.4)$ \\
\hline Clinical enthesitis, $\mathrm{n}(\%)$ & $25(62.5)$ & $24(66.7)$ & $49(64.5)$ \\
\hline Fulfilled New York criteria, $\mathrm{n}(\%)^{20}$ & $20(50)$ & $19(52.8)$ & $39(51.3)$ \\
\hline
\end{tabular}

For further baseline data see tables 2 and 3 .

CRP, C-reactive protein (reference range $<5 \mathrm{mg} / \mathrm{l}$ ).

Table 2 MRI scores of sacroiliac joints, spine, enthesitis and posterior segments of the spine at baseline, week 24 and at week 48 in the etanercept versus sulfasalazine treatment group

\begin{tabular}{|c|c|c|c|c|}
\hline Parameters assessed & Time & Etanercept group $(n=40)$ & Sulfasalazine group $(n=36)$ & p Value* \\
\hline \multirow[t]{3}{*}{ MRI sacroiliac joint score (0-24), mean (SD) } & Baseline $^{\dagger}$ & $7.8(6.3)$ & $5.4(5.1)$ & \\
\hline & Week 24 & $3.1(3.6)$ & $3.7(3.2)$ & 0.006 \\
\hline & Week 48 & $2.4(3.2)$ & $3.5(3.8)$ & 0.02 \\
\hline \multirow[t]{3}{*}{ MRI spine score (0-69), mean (SD) } & Baseline $^{\dagger}$ & $2.3(3.5)$ & $1.4(3.1)$ & \\
\hline & Week 24 & $1.4(3.1)$ & $1.5(3.1)$ & 0.03 \\
\hline & Week 48 & $1.0(2.1)$ & $1.3(2.9)$ & 0.01 \\
\hline \multirow[t]{3}{*}{ MRI enthesitis ${ }^{\ddagger}$} & Baseline $^{\dagger}$ & 26 sites (in 15 patients) & 24 sites (in 16 patients) & \\
\hline & Week 24 & 22 sites (in 12 patients) & 23 sites (in 14 patients) & 0.67 \\
\hline & Week 48 & 11 sites (in 11 patients) & 26 sites (in 14 patients) & 0.04 \\
\hline \multirow[t]{3}{*}{ MRI posterior segments of the spine } & Baseline $^{\dagger}$ & 37 sites (in 9 patients) & 18 sites (in 4 patients) & \\
\hline & Week 24 & 30 sites (in 4 patients) & 13 sites (in 2 patients) & 0.78 \\
\hline & Week 48 & 26 sites (in 2 patients) & 13 sites (in 1 patient) & 0.92 \\
\hline
\end{tabular}

${ }^{*} \mathrm{p}$ Values for comparison of changes in the MRI scores between both groups by analysis of covariance.

${ }^{\dagger}$ No significant differences at baseline between etanercept and sulfasalazine: sacroiliac joints $(p=0.06)$, spine $(p=0.09)$, enthesitis $(p=0.50)$, posterior segments $(p=0.25)$.

${ }^{\ddagger}$ Only active osteitis (hyperintense bone signal in the STIR sequence) was scored as enthesitis.
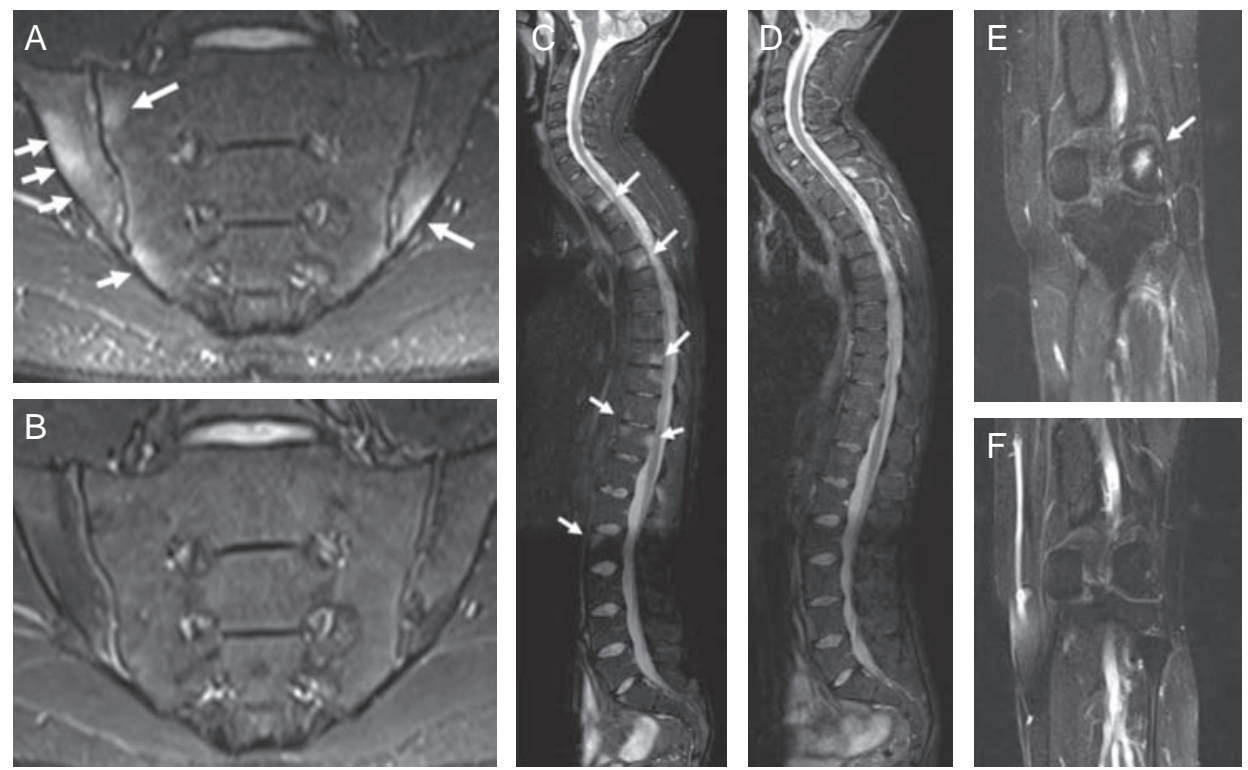

Figure 1 Examples for MRI before and after 48 weeks of treatment with etanercept: (a) sacroiliac joints: baseline MRI, sacroiliac joint score 15.5 (A), week $48 \mathrm{MRI}$, sacroiliac joint score 0 (B); (b) spine, baseline MRI spine score 11.5 (C), week $48 \mathrm{MRI}$ spine score 1 (D); (c) enthesitis of lateral condyle of femur of right knee (dorsal view), MRI baseline with enthesitis (E), week 48 without enthesitis (F). 
Table 3 Efficacy data at baseline, week 24 and at week 48 in the etanercept versus sulfasalazine treatment group

\begin{tabular}{|c|c|c|c|c|}
\hline Parameters assessed & Time & Etanercept group $(n=40)$ & Sulfasalazine group $(n=36)$ & p Value* \\
\hline \multirow[t]{3}{*}{ BASDAI (0-10), mean ( \pm SD) } & Baseline $^{\dagger}$ & $5.5(1.3)$ & $6.0(1.2)$ & \\
\hline & Week 24 & $2.6(2.3)$ & $4.4(2.2)$ & 0.002 \\
\hline & Week 48 & $2.5(2.0)$ & $4.4(2.4)$ & 0.001 \\
\hline \multirow{3}{*}{ BASFI (0-10), mean ( \pm SD) } & Baseline $^{\dagger}$ & $4.3(2.3)$ & $4.3(1.8)$ & \\
\hline & Week 24 & $1.9(2.2)$ & $3.1(2.2)$ & 0.005 \\
\hline & Week 48 & $2.0(2.1)$ & $3.3(2.2)$ & 0.001 \\
\hline \multirow[t]{3}{*}{ Patient global $(0-10)$, mean $( \pm S D)$} & Baseline $^{\dagger}$ & $6.7(2.1)$ & $7.1(1.6)$ & \\
\hline & Week 24 & $2.6(2.6)$ & $5.1(2.5)$ & $<0.001$ \\
\hline & Week 48 & $2.6(2.2)$ & $4.9(3.0)$ & $<0.001$ \\
\hline \multirow[t]{3}{*}{ Physician global $(0-10)$, mean $( \pm S D)$} & Baseline $^{\dagger}$ & $6.4(1.2)$ & $6.1(1.5)$ & \\
\hline & Week 24 & $1.8(1.9)$ & $3.8(2.5)$ & $<0.001$ \\
\hline & Week 48 & $1.8(1.8)$ & $4.1(2.9)$ & $<0.001$ \\
\hline \multirow[t]{3}{*}{ Joint count $(0-64)$, mean $( \pm S D)$} & Baseline $^{\dagger}$ & $2.3(5.8)$ & $1.3(1.7)$ & \\
\hline & Week 24 & $0.3(1.3)$ & $0.4(2.0)$ & 0.70 \\
\hline & Week 48 & $0.2(0.7)$ & $0.3(1.5)$ & 0.48 \\
\hline \multirow[t]{3}{*}{ Enthesitis score $(0-17)$, mean $( \pm S D)$} & Baseline $^{\dagger}$ & $4.4(4.6)$ & $3.4(3.4)$ & \\
\hline & Week 24 & $1.6(4.1)$ & $2.6(3.6)$ & 0.01 \\
\hline & Week 48 & $1.8(4.2)$ & $1.4(2.9)$ & 0.70 \\
\hline \multirow{3}{*}{ BASMI (0-10), mean ( $\pm S D)$} & Baseline $^{\dagger}$ & $1.9(1.7)$ & $1.7(1.4)$ & \\
\hline & Week 24 & $1.7(1.6)$ & $1.9(1.6)$ & 0.28 \\
\hline & Week 48 & $1.6(1.8)$ & $1.9(1.7)$ & 0.32 \\
\hline \multirow[t]{3}{*}{$\mathrm{EQ}-5 \mathrm{D}(0-1)$, mean $( \pm \mathrm{SD})$} & Baseline $^{\dagger}$ & $0.6(0.3)$ & $0.6(0.3)$ & \\
\hline & Week 24 & $0.9(0.2)$ & $0.7(0.2)$ & 0.01 \\
\hline & Week 48 & $0.8(0.2)$ & $0.7(0.3)$ & 0.047 \\
\hline \multirow[t]{3}{*}{ AS-OoL (0-18), mean $( \pm S D)$} & Baseline $^{\dagger}$ & $9.7(4.5)$ & $9.3(3.6)$ & \\
\hline & Week 24 & $4.1(4.3)$ & $7.4(5.0)$ & $<0.001$ \\
\hline & Week 48 & $4.4(4.8)$ & $7.5(5.4)$ & $<0.001$ \\
\hline \multirow[t]{3}{*}{ CRP (ref 5 mg/l), mean ( \pm SD) } & Baseline $^{\dagger}$ & $11.9(13.2)$ & $10.6(14.9)$ & \\
\hline & Week 24 & $4.2(3.5)$ & $8.5(11.8)$ & 0.07 \\
\hline & Week 48 & $4.3(3.7)$ & $8.7(12.5)$ & 0.13 \\
\hline
\end{tabular}

\footnotetext{
* $p$ Values for comparison of changes in the parameters between both groups by analysis of covariance.
}

${ }^{\dagger}$ No significant differences at baseline between etanercept and sulfasalazine. Every mean value refers to the complete intention-to-treat population (etanercept, $\mathrm{n}=40$; sulfasalazine, $\mathrm{n}=36)$.

ASQoL, ankylosing spondylitis quality of life questionnaire; BASDAI, Bath ankylosing spondylitis disease activity index; BASFI, Bath ankylosing spondylitis disease functional index;

BASMI, Bath ankylosing spondylitis metrology index; CRP, C-reactive protein (reference range $<5 \mathrm{mg} / \mathrm{l}$ ); EQ-5D, Euro0oL index.

As shown in table 2, active inflammation in the posterior segments of the spine was present in 13 patients (17.1\%). There was a reduction from 37 to 26 sites in the etanercept group between baseline and week 48 versus from 18 to 13 sites in the sulfasalazine group; however, this difference was not significant (table 2). Enthesitis was present in 31 patients $(40.8 \%)$ at baseline. The number of enthesitic sites was reduced significantly by $58 \%$ at week 48 in the etanercept group, whereas there was no reduction in the sulfasalazine group ( $p=0.04$ for the difference between the two groups; table 2).

\section{Secondary clinical outcome parameters}

The analysis of the clinical efficacy data showed a statistically significant reduction of all analysed variables in the etanercept in comparison with the sulfasalazine treatment group, except for the BASMI, swollen joints, clinical enthesitis and CRP (table 3 and figure 3 ).

There was a significant correlation between changes in BASDAI and BASFI and changes in the MRI sacroiliac joint scores ( $p$ values were 0.04 and 0.0069 , respectively), but not for CRP. However, there was no significant correlation between MRI enthesitis and MRI spine scores and clinical parameters.

Of the six patients who became completely free of inflammation both in the sacroiliac joints and spine in the etanercept group, all patients were also in clinical remission according to the ASAS criteria (15.4\% of the whole etanercept-group). In contrast, none of the two patients reaching remission in the sulfasalazine group $(0 \%)$ was free of inflammation as shown by whole-body MRI, a significant difference between the groups $(\mathrm{p}=0.03)$.

When the whole group was separated into patients with AS and patients with non-radiographic axial spondyloarthritis there were no clear differences for the reduction in MRI scores and clinical parameters (data not shown).

\section{Dropouts}

Seven dropouts were noted before week 24 , another three before week 48, among them five each in the etanercept group (two wishes for pregnancy, three lost to follow-up), and the sulfasalazine group (two lost to follow-up, one discontinuation because of side-effects and lack of efficacy and one patient because of new lymphoma).

\section{Safety}

Three hundred and twenty-one adverse events (AE) occurring in 71 patients were reported (167 AE in 39 etanercept patients and $154 \mathrm{AE}$ in 32 sulfasalazine patients). Infections of the respiratory tract were the most frequently reported AE. In total, there were three serious $\mathrm{AE}$ in the etanercept group and seven in the sulfasalazine group. Among the serious AE only three were regarded as potentially treatment related (one etanercept and two sulfasalazine patients).

\section{DISCUSSION}

In the present study we performed the most comprehensive analysis so far of the response of active inflammation, as shown by MRI, to treatment with a TNF blocker in comparison with 

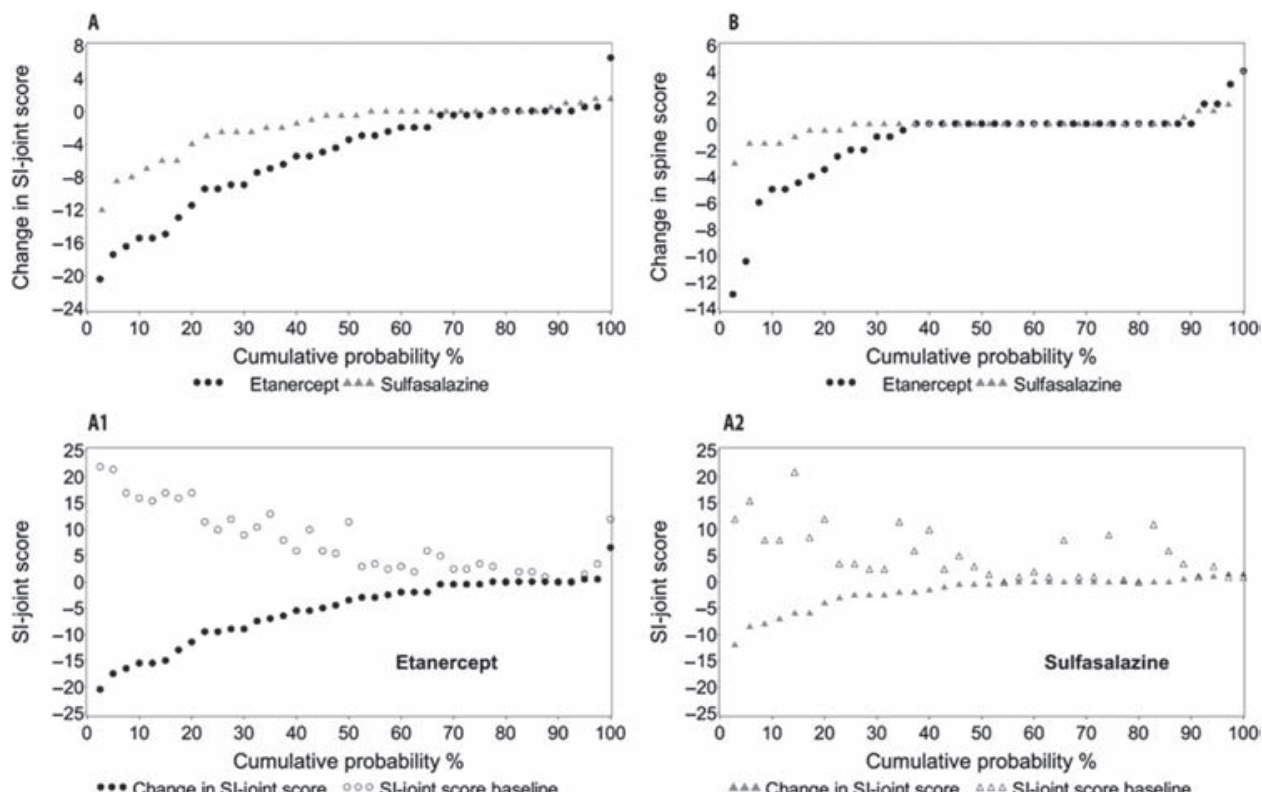

Figure 2 Cumulative probability of changes in MRI activity scores of the sacroiliac (SI) joints (A) and the spine (B) from baseline to week 48 in the etanercept and sulfasalazine treatment groups. Each data point in A and B represents an individual patient. For sacroiliac joint scores, double probability plots for the etanercept group (A1) and the sulfasalazine group (A2) are shown, with the baseline MRI activity score for each patient plotted above the corresponding change scores from baseline to week 48 .

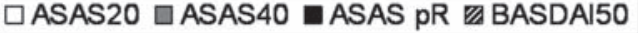

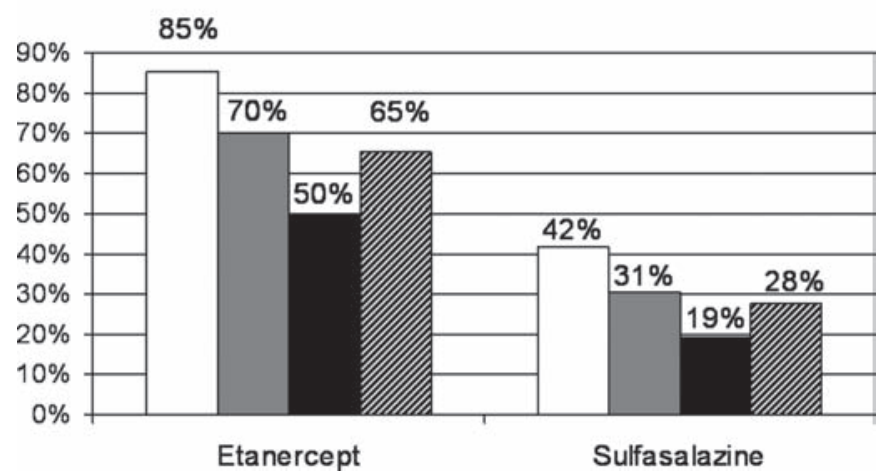

Figure 3 Response of the Assessment of SpondyloArthritis International Society (ASAS) criteria for $20 \%$ improvement in disease activity (ASAS20), the ASAS40, the ASAS criteria for partial remission $(\mathrm{Pr})$, and the Bath ankylosing spondylitis disease activity index criteria for 50\% improvement (BASDAI50) in week 48 after treatment with etanercept $(n=40)$ or sulfasalazine $(n=36)$ in patients with active axial spondyloarthritis. Significantly more patients from the etanercept group compared with the sulfasalazine group reached ASAS20 (85\%, $95 \% \mathrm{Cl} 70.7 \%$ to $93.3 \%$ vs $42 \%, 95 \% \mathrm{Cl} 25.5 \%$ to $59.2 \%$; $p=0.001)$, ASAS 40 (70\%, $95 \%$ Cl $54.2 \%$ to $83.4 \%$ vs $31 \%, 95 \%$ CI $17.7 \%$ to $46.6 \%$; $\mathrm{p}=0.001)$, ASAS partial remission $(50 \%, 95 \% \mathrm{Cl} 34.4 \%$ to $65.6 \%$ vs $19 \%$, $95 \% \mathrm{Cl} 8.5 \%$ to $35.5 \% ; \mathrm{p}=0.006)$ and BASDAI50 (65\%, $95 \% \mathrm{Cl} 48.3 \%$ to $78.8 \%$ vs $28 \%, 95 \% \mathrm{Cl} 14.2 \%$ to $43.6 \% ; p=0.001$ ).

sulfasalazine treatment over 1 year in patients with axial spondyloarthritis. In these patients with a symptom duration of less than 5 years most inflammation was found in the sacroiliac joints in comparison with the spine or other extraspinal sites. Accordingly, a larger improvement in sacroiliac joint inflammation was observed compared with spinal inflammation when patients were treated with etanercept (table 2), but the differences compared with the sulfasalazine group were clearly significant both for the sacroiliac joint and spine at week 24 and at week 48.
The current study can best be compared with an infliximab trial in axial spondyloarthritis patients with a symptom duration of less than 3 years, which also showed a good reduction of active inflammation on MRI. ${ }^{10}$

In the study mentioned above, ${ }^{10}$ an improvement in the spinal inflammation was also reported, but only the presence or absence of inflammation per spinal area was scored without further quantification and without differentiation of inflammation found in the vertebral body and the posterior segment.

There was no clear difference between the two treatment groups in the reduction of inflammation present in the posterior segments of the spine (table 2 ) in the present study, which may be due to the small percentage of patients in whom the posterior segment was involved. The $17 \%$ positive patients at baseline in our study are different from previous reports, which found inflammation at this site in a higher percentage of patients. 3839

So far only one whole-body MRI study has tried to score inflammatory sites other than spine and sacroiliac joints in patients with axial spondyloarthritis. ${ }^{40}$ In that study only the shoulder and pelvic girdles and the anterior chest wall were included, whereas the lower extremities were left out, although they are frequently affected in spondyloarthritis. Therefore, again the current study is the first one to include these sites and, even more importantly, to investigate inflammation in a blinded controlled fashion over 1 year of treatment with etanercept compared with sulfasalazine.

Enthesitis by MRI was found in $40.8 \%$ of patients, a frequency lower than clinically evident enthesitis (table 1). Most interestingly, the number of enthesitic sites was reduced by nearly $58 \%$ (table 2) at week 48 in the etanercept group, a percentage similar to the reduction in inflammation observed in the sacroiliac joints and spine. On the other hand, there was no reduction in the sulfasalazine group, supporting the view that inflammation in sacroiliac joints, spine and enthesitic sites has a very similar immunopathology and response to treatment. ${ }^{41} 42$ Until now only one other controlled study showed a favourable effect of a TNF blocker, in this case also etanercept, on enthesitis as shown by MRI. ${ }^{43}$ 
Because only the reading of the MRI and not treatment was blinded, the clinical response was only analysed as a secondary outcome parameter. Obviously, a double-blind controlled trial would have been preferable, but was not feasible for logistic and economic reasons. Sulfasalazine was chosen because this was the only non-biological conventional drug for which there were some response signals in previous trials with active AS patients failing NSAID therapy, ${ }^{44-47}$ justifying a 1-year treatment phase. Despite the limitations of the interpretations of the clinical results because of the open-label design, there were some interesting results (table 3 ). In this cohort of early axial spondyloarthritis patients ASAS partial remission was reached in $50 \%$ of patients already after 24 weeks and maintained over 48 weeks, a result very similar to the $55.5 \%$ remission rate in the other early axial spondyloarthritis trial, ${ }^{10}$ clearly indicating that a remission rate similar to that found in early rheumatoid arthritis ${ }^{48}$ can also be achieved in early axial spondyloarthritis patients treated with a TNF blocker. In a previous adalimumab trial in those patients with non-radiographic axial spondyloarthritis ${ }^{7}$ with a disease duration less than 3 years, the remission rate was close to the figure reported here, indicating that the symptom duration may be more relevant than the presence or absence of chronic changes seen by x-rays. ${ }^{7}$

When MRI and clinical data were correlated, all six patients in the etanercept group who became free from any active MRI inflammation were also in clinical remission (out of 20), although neither of the two patients in the sulfasalazine group was in remission. Also the mean sacroiliac joint score had a greater reduction in the etanercept patients reaching remission (from 8.4 to 1.8) than in the whole etanercept group (from 5.4 to 3.5). A similar difference in correlation with the clinical response was not seen in the sulfasalazine group. It remains to be seen whether the number of patients who become free of any bony inflammation will increase if patients are treated with a TNF blocker beyond 1 year. Interestingly, a significant correlation between change in MRI sacroiliac joint scores and BASDAI and BASFI was observed for the first time.

These data indicate that the differences seen in the clinical response rate between the etanercept and the sulfasalazine groups might be real, and that there is a correlation between bony inflammation on MRI and clinical response, as nicely shown in the very good etanercept responders. A planned follow-up of those patients who are free of symptoms and of inflammation on MRI will address the question of how many of these patients will have reached drug-free remission. Furthermore, an additional analysis of structural changes as shown on the T1 sequence of the MRI will cast more light on the rather complex interaction between inflammation and structural damage in this disease. ${ }^{49}$

The observed clinical effect found in the sulfasalazine arm did not exceed the observed placebo remission response of $12.5 \%$ at week 16 in the trial of Barkham et allo or the observed sulfasalazine remission response of $15.5 \%$ at week 16 in a recent double-blind trial in active AS patients comparing etanercept with sulfasalazine. ${ }^{50}$ The small improvement of MRI inflammation, as observed in the sacroiliac joints but not in the spine or entheses, might be by chance. Therefore, both the blinded MRI data and the unblinded clinical data support earlier evidence ${ }^{51}$ that sulfasalazine does not appear to play an important role in the treatment of AS and/or early axial spondyloarthritis.

Interestingly, although in earlier AS trials short disease duration, elevated CRP and positive MRI were predictors of a good clinical response, ${ }^{5-7}$ no such predictors were found in the current study, most probably because only patients with a short disease duration and positive MRI were included, which are themselves already strong predictors of a good response.
In conclusion, in this early axial spondyloarthritis trial over 1 year, etanercept, in comparison with sulfasalazine, improved bony inflammation at different sites of the skeleton considerably, in parallel to an observed clinical improvement. These results suggest that TNF blockers in axial spondyloarthritis patients are effective when patients are treated early.

Acknowledgement The authors would like to thank Beate Buss, Gabriela Schmittat, Kirsten Karberg, Jan Brandt, Eugen Feist, Jan Zernicke, Barbara Wenzel, Carmen Herz, Corinna Beer, Angela Seifert, Rieke Alten, Svetlana D'jacenko, Christof Pohl, Marina Heese, Silke Zinke, Kristin Lunkwitz, Ulrich Prothmann, Ute Alpermann, Thilo Klopsch, Frank Mielke and Martina Stoll for performing the studies. The authors also thank Sabine Achtelstetter and Anja Weiss for data preparation and statistical analysis. They would also like to thank Torsten Diekhoff for blinding and the preparation of magnetic resonance images.

Funding This study was supported by an unrestricted grant from by Wyeth, which was acquired by Pfizer Inc in October 2009.

Competing interests IS and HH: Wyeth Pharmaceuticals, Merck Sharp Dohme/ Schering Plough, Abbott Immunology Pharmaceuticals: consulting fees or other remuneration. GB, MR and JS: Wyeth Pharmaceuticals, Merck Sharp Dohme/ Schering Plough, Abbott Immunology Pharmaceuticals, UCB: consulting fees or other remuneration. AK: Wyeth Pharmaceuticals, Schering Plough, Abbott Immunology Pharmaceuticals: consulting fees or other remuneration. MB: Merck Sharp Dohme/ Schering Plough, Abbott Immunology Pharmaceuticals: consulting fees or other remuneration. BF: Former employee of Pfizer/Wyeth. KGH, CA and JL: none.

\section{Patient consent Obtained.}

Ethics approval This study was conducted with the approval of the Landesamt für Gesundheit und Soziales, Geschäftsstelle der Ethik-Kommission des Landes Berlin, Sächsische Strasse 28, 10707 Berlin, Germany.

Provenance and peer review Not commissioned; externally peer reviewed.

\section{REFERENCES}

1. van der Heijde D, Dijkmans B, Geusens $P$, et al. Efficacy and safety of infliximab in patients with ankylosing spondylitis: results of a randomized, placebo-controlled trial (ASSERT). Arthritis Rheum 2005;52:582-91.

2. Davis JC Jr, Van Der Heijde D, Braun J, et al. Recombinant human tumor necrosis factor receptor (etanercept) for treating ankylosing spondylitis: a randomized, controlled trial. Arthritis Rheum 2003;48:3230-6.

3. van der Heijde D, Kivitz A, Schiff MH, et al. Efficacy and safety of adalimumab in patients with ankylosing spondylitis: results of a multicenter, randomized, doubleblind, placebo-controlled trial. Arthritis Rheum 2006;54:2136-46.

4. Braun J, Brandt J, Listing J, et al. Treatment of active ankylosing spondylitis with infliximab: a randomised controlled multicentre trial. Lancet 2002;359:1187-93.

5. Rudwaleit M, Listing J, Brandt J, et al. Prediction of a major clinical response (BASDAI 50) to tumour necrosis factor alpha blockers in ankylosing spondylitis. Ann Rheum Dis 2004;63:665-70.

6. Rudwaleit M, Claudepierre P, Wordsworth P, et al. Effectiveness, safety, and predictors of good clinical response in 1250 patients treated with adalimumab for active ankylosing spondylitis. J Rheumatol 2009;36:801-8.

7. Haibel H, Rudwaleit M, Listing J, et al. Efficacy of adalimumab in the treatment of axial spondylarthritis without radiographically defined sacroiliitis: results of a twelveweek randomized, double-blind, placebo-controlled trial followed by an open-label extension up to week fifty-two. Arthritis Rheum 2008;58:1981-91.

8. Rudwaleit M, van der Heijde D, Landewé R, et al. The development of Assessment of SpondyloArthritis international Society classification criteria for axial spondyloarthritis (part II): validation and final selection. Ann Rheum Dis 2009;68:777-83.

9. Rudwaleit M, Jurik AG, Hermann KG, et al. Defining active sacroiliitis on magnetic resonance imaging (MRI) for classification of axial spondyloarthritis: a consensual approach by the ASAS/OMERACT MRI group. Ann Rheum Dis 2009;68:1520-7.

10. Barkham N, Keen HI, Coates LC, et al. Clinical and imaging efficacy of infliximab in HLA-B27-positive patients with magnetic resonance imaging-determined early sacroiliitis. Arthritis Rheum 2009;60:946-54

11. Braun J, Landewé $R$, Hermann $K G$, et al. Major reduction in spinal inflammation in patients with ankylosing spondylitis after treatment with infliximab: results of a multicenter, randomized, double-blind, placebo-controlled magnetic resonance imaging study. Arthritis Rheum 2006;54:1646-52.

12. Althoff CE, Appel H, Rudwaleit M, et al. Whole-body MRI as a new screening tool for detecting axial and peripheral manifestations of spondyloarthritis. Ann Rheum Dis 2007;66:983-5.

13. Appel H, Hermann KG, Althoff CE, et al. Whole-body magnetic resonance imaging evaluation of widespread inflammatory lesions in a patient with ankylosing spondylitis before and after 1 year of treatment with infliximab. J Rheumatol 2007;34:2497-8. 
14. Mager AK, Althoff CE, Sieper J, et al. Role of whole-body magnetic resonance imaging in diagnosing early spondyloarthritis. Eur J Radiol 2009;71:182-8.

15. Weber U, Maksymowych WP, Jurik AG, et al. Validation of whole-body against conventional magnetic resonance imaging for scoring acute inflammatory lesions in the sacroiliac joints of patients with spondylarthritis. Arthritis Rheum 2009;61:893-9.

16. Weber U, Hodler J, Jurik AG, et al. Assessment of active spinal inflammatory changes in patients with axial spondyloarthritis: validation of whole body MRI against conventional MRI. Ann Rheum Dis 2010;69:648-53.

17. Carbone LD, Cooper C, Michet CJ, et al. Ankylosing spondylitis in Rochester, Minnesota, 1935-1989. Is the epidemiology changing? Arthritis Rheum 1992;35:1476-82.

18. Calin A, Porta J, Fries JF, et al. Clinical history as a screening test for ankylosing spondylitis. JAMA 1977;237:2613-14.

19. Dougados M, van der Linden S, Juhlin R, et al. The European Spondylarthropathy Study Group preliminary criteria for the classification of spondylarthropathy. Arthritis Rheum 1991;34:1218-27.

20. van der Linden S, Valkenburg HA, Cats A. Evaluation of diagnostic criteria for ankylosing spondylitis. A proposal for modification of the New York criteria. Arthritis Rheum 1984;27:361-8.

21. Garrett S, Jenkinson T, Kennedy LG, et al. A new approach to defining disease status in ankylosing spondylitis: the Bath Ankylosing Spondylitis Disease Activity Index. J Rheumatol 1994;21:2286-91.

22. Anderson JJ, Baron G, van der Heijde D, et al. Ankylosing spondylitis assessment group preliminary definition of short-term improvement in ankylosing spondylitis. Arthritis Rheum 2001;44:1876-86.

23. Brandt J, Listing J, Sieper J, et al. Development and preselection of criteria for short term improvement after anti-TNF alpha treatment in ankylosing spondylitis. Ann Rheum Dis 2004;63:1438-44.

24. Sieper J, Rudwaleit M, Baraliakos X, et al. The Assessment of SpondyloArthritis international Society (ASAS) handbook: a guide to assess spondyloarthritis. Ann Rheum Dis 2009;68(Suppl 2):ii1-44.

25. Calin A, Garrett S, Whitelock $H$, et al. A new approach to defining functional ability in ankylosing spondylitis: the development of the Bath Ankylosing Spondylitis Functional Index. J Rheumatol 1994;21:2281-5.

26. van der Heijde D, Landewé R, Feldtkeller E. Proposal of a linear definition of the Bath Ankylosing Spondylitis Metrology Index (BASMI) and comparison with the 2-step and 10-step definitions. Ann Rheum Dis 2008:67:489-93.

27. Heuft-Dorenbosch L, Spoorenberg A, van Tubergen A, et al. Assessment of enthesitis in ankylosing spondylitis. Ann Rheum Dis 2003;62:127-32.

28. Rudwaleit M, Haibel H, Baraliakos $X$, et al. The early disease stage in axial spondylarthritis: results from the German Spondyloarthritis Inception Cohort. Arthritis Rheum 2009:60:717-27.

29. Ware JE Jr, Sherbourne CD. The MOS 36-item short-form health survey (SF-36). I. Conceptual framework and item selection. Med Care 1992;30:473-83.

30. Hurst NP, Kind P, Ruta D, et al. Measuring health-related quality of life in rheumatoid arthritis: validity, responsiveness and reliability of EuroOol (EQ-5D). Br J Rheumatol 1997;36:551-9.

31. Doward LC, Spoorenberg A, Cook SA, et al. Development of the ASQoL: a quality of life instrument specific to ankylosing spondylitis. Ann Rheum Dis 2003;62:20-6.

32. Hermann KG, Braun J, Fischer T, et al. [Magnetic resonance tomography of sacroiliitis: anatomy, histological pathology, MR-morphology, and grading]. Radiologe 2004;44:217-28.

33. van der Heijde $\mathbf{D}$, Landewé $\mathrm{R}$, Hermann $\mathrm{KG}$, et al. Is there a preferred method for scoring activity of the spine by magnetic resonance imaging in ankylosing spondylitis? J Rheumatol 2007:34:871-3.
34. Haibel H, Rudwaleit M, Brandt HC, et al. Adalimumab reduces spinal symptoms in active ankylosing spondylitis: clinical and magnetic resonance imaging results of a fifty-two-week open-label trial. Arthritis Rheum 2006;54:678-81.

35. Rudwaleit M, Schwarzlose S, Hilgert ES, et al. MRI in predicting a major clinica response to anti-tumour necrosis factor treatment in ankylosing spondylitis. Ann Rheum Dis 2008;67:1276-81.

36. Bathke A, Brunner E. A nonparametric alternative to analysis of covariance. In: Akritas MG, Politis DN, eds. Recent advances and trends in nonparametric statistics. Amsterdam: Elsevier Science and Technology 2003:109-20.

37. Holm S. A simple sequentially rejective multiple test procedure. Scand J Statist 1979;6:65-70.

38. Bochkova AG, Levshakova AV, Bunchuk NV, et al. Spinal inflammation lesions as detected by magnetic resonance imaging in patients with early ankylosing spondylitis are more often observed in posterior structures of the spine. Rheumatology (Oxford) 2010;49:749-55

39. Maksymowych WP, Crowther SM, Dhillon SS, et al. Systematic assessment of inflammation by magnetic resonance imaging in the posterior elements of the spine in ankylosing spondylitis. Arthritis Care Res (Hoboken) 2010;62:4-10.

40. Weber U, Pfirrmann CW, Kissling RO, et al. Whole body MR imaging in ankylosing spondylitis: a descriptive pilot study in patients with suspected early and active confirmed ankylosing spondylitis. BMC Musculoskelet Disord 2007;8:20.

41. McGonagle D, Marzo-Ortega H, O'Connor P, et al. Histological assessment of the early enthesitis lesion in spondyloarthropathy. Ann Rheum Dis 2002:61:534-7.

42. Maksymowych WP. Ankylosing spondylitis - at the interface of bone and cartilage J Rheumatol 2000;27:2295-301.

43. Dougados $\mathbf{M}$, Combe B, Braun J, et al. A randomised, multicentre, double-blind placebo-controlled trial of etanercept in adults with refractory heel enthesitis in spondyloarthritis: the HEEL trial. Ann Rheum Dis 2010;69:1430-5.

44. Feltelius $\mathbf{N}$, Hällgren R. Sulphasalazine in ankylosing spondylitis. Ann Rheum Dis 1986;45:396-9.

45. Dougados M, Boumier P, Amor B. Sulphasalazine in ankylosing spondylitis: a double blind controlled study in 60 patients. BMJ (Clin Res Ed) 1986;293:911-14.

46. Nissilä M, Lehtinen K, Leirisalo-Repo M, et al. Sulfasalazine in the treatment of ankylosing spondylitis. A twenty-six-week, placebo-controlled clinical trial. Arthritis Rheum 1988;31:1111-16.

47. Davis MJ, Dawes PT, Beswick E, et al. Sulphasalazine therapy in ankylosing spondylitis: its effect on disease activity, immunoglobulin $A$ and the complex immunoglobulin A-alpha-1-antitrypsin. Br J Rheumatol 1989;28:410-13.

48. Emery P, Breedveld FC, Hall S, et al. Comparison of methotrexate monotherapy with a combination of methotrexate and etanercept in active, early, moderate to severe rheumatoid arthritis (COMET): a randomised, double-blind, parallel treatment trial. Lancet 2008;372:375-82.

49. Sieper J, Appel H, Braun J, et al. Critical appraisal of assessment of structural damage in ankylosing spondylitis: implications for treatment outcomes. Arthritis Rheum 2008:58:649-56.

50. Braun J, Pavelka K, Remus CR, et al. Clinical efficacy of etanercept versus sulfasalazine in ankylosing spondylitis patients with peripheral joint involvement. Ann Rheum Dis 2009;68:627.

51. Braun J, Zochling J, Baraliakos X, et al. Efficacy of sulfasalazine in patients with inflammatory back pain due to undifferentiated spondyloarthritis and early ankylosing spondylitis: a multicentre randomised controlled trial. Ann Rheum Dis 2006:65:1147-53. 
I-H Song, KG Hermann, H Haibel et al. Effects of etanercept versus sulfasalazine in early axial spondyloarthritis on active inflammatory lesions as detected by whole-body MRI (ESTHER): a 48-week randomised controlled trial. Ann Rheum Dis 2011;70:590-596. doi:10.1136/ard. 2010.139667. The name of the author, C E Althoff was incorrectly published as CE Althoff.

Ann Rheum Dis 2011;70:1350. doi:10.1136/ard.2010.139667corr1 